\title{
Resistance to treatment in eating disorders: a critical challenge
}

\author{
Secondo Fassino ${ }^{*}$ and Giovanni Abbate-Daga
}

\begin{abstract}
The Special Issue "Treatment resistance in Eating Disorders" gathers together the contributions provided by several experienced groups of researchers in the field of Eating Disorders (EDs). The main topic is addressed from multiple perspectives ranging from pathogenesis (including developmental and maintaining factors) to treatment. An explicative model of resistance in EDs is also proposed.
\end{abstract}

The mind commands the body, and it obeys instantly; the mind commands itself, and is resisted [...]. And therefore are there two wills, for that one of them is not entire: and what the one lacketh, the other hath. (Augustine of Hippo AD 398; Confessions)

Challenging resistance to treatment has now become crucial in psychiatric clinical practice also because of the relevance of this topic from a public health standpoint. In fact, research has recently highlighted that other psychiatric illnesses like schizophrenia, depression and bipolar disorders, obsessive-compulsive disorders, and personality disorders are often characterized by either a lack of effect or a moderate response to treatments [1].

Eating Disorders (EDs) are serious and difficult to treat mental illnesses, often showing ego-syntonic features and resistance to treatments; as a result, a chronic course of illness occurs in a considerable number of affected individuals [2]. To date there is a lack of evidence-based treatments effectively impacting the ED outcome [3,4] and therapy is often hampered by the well-known phenomenon of dropout [5].

At the onset of the ED, affected individuals are only rarely aware of their illness and such an attitude can be maintained until death [6]. Some of the aspects contributing to denial and resistance to treatments can be automatic and unmotivated whilst others are consciously generated by patients who actively oppose to treatment,

\footnotetext{
* Correspondence: secondo.fassino@unito.it

Eating Disorders Center for Treatment and Research, Department of Neuroscience, University of Turin, Via Cherasco 15, Turin 10126, Italy
}

also on the basis of the biological vulnerability of altered reward and inhibition underlying these disorders $[7,8]$.

The ED field could represent an example of both crisis of psychiatry and its moderate effectiveness $[9,10]$ with reductionist approaches also playing a role in this regard [11]. Hence new complex models that take into account the intertwined link between psychology and its biological underpinnings are necessary to better understand these disorders. For example, more emphasis should be placed on the neurobiology of interpersonal relationships and on how treatments can modify the brain from both individual and evolutionary perspective [12].

In the framework of resistance to treatments in EDs, the psychodynamic model suggested in the past by A. Adler, H. Kohut, and D. W. Winnicott seems to be reconceptualized by recent findings, with the EDs emerging in the present articles as disorders of the development of the Self, as already theorized [13,14]. Prompted by earlier lines of research, studies have recently focused on several aspects including: neurobiological effects of attachment and primary relationships, complex gene-environment interaction, temperament and deficits in the development of the character, cognitive inflexibility, and those pseudopositive meaning that patients attribute to their behaviors and symptoms.

Figure 1 illustrates the EDs as developmental disorders and the vicious cycle that is elicited and maintained by the "ED identity", potentially a crucial issue in generating resistance. Disorientation and distress that characterize patients since childhood and that are then triggered during adolescence have been graphically emphasized. The biopsychosocial factors that interfere with a mature 




development of the Self and those aspects that hamper an adaptive personality development are also highlighted. This approach suggests a distinction between mere eating symptomatology (as conceptualized by the Diagnostic and Statistical Manual criteria) and the profound nature and meaning of these disorders. In line with this approach, the ED symptomatology can be severe and overwhelming but the triggering core of the disorder could be represented instead by a primary and multifaceted deficit of personality development. During adolescence, such a deficit could be involved in generating eating symptomatology as both signal of suffering and harmful attempt to self-cure. The process/vicious cycle is graphically represented as reinforced by contaminant emotions [15]: conscious and unconscious meanings, family dynamics, starvation, countertransference and therapist's reactions, anger, and aggressiveness; all these factors can lead to a chronic course of the disorder.
In other words, such an impaired development could lead to eating symptomatology as a pseudo-adaptive response to profound worthlessness $[13,16,17]$ and to the inability to integrate inner states and external stimuli. This feeling of inferiority is then exaggerated by the illness, with starvation and splitting and obsessive thoughts reinforcing patients' perfectionistic premorbid traits. Therefore, relational and decision-making abilities are further impaired along with feelings of anger and loneliness.

Within this framework, eating symptomatology mirrors inner ambivalence: on one hand eating behaviors indicate severe psychological discomfort and on the other hand dangerously mask the conflicts that typically occur during adolescence (dependence-independence, gender identification, creativity-shame, etc.). A vicious cycle leading to avoidance can be generated by two aspects: the first is the need to control hunger and weight as a means of regaining self-esteem, and the second is 
represented by the fear of losing control on eating, life, and emotions [18].

Therefore, from a clinical standpoint, the understanding of the adaptive value of eating symptomatology is crucial to help clinicians considering those needs and conflicts underlying the disorder and to plan shared treatment interventions and goals. An innovative approach to psychiatry should encourage patients to use their own resources to change, hence entailing lower distress in therapy [9]. Moreover, treatment should help patients understand what underlies their illness and also provide alternative motivations and strategies to give up the disorder. In line with treatments for other mental disorders, also in the ED field psychotherapists should encourage patients to use understanding and kindness toward themselves and others as a way to overcome the burden of emaciation, negative emotionality, and avoidance [12].

Since resistance can be also considered as a regulator of the therapeutic relationship, therapists should address this issue being aware of transference and countertransference, and carefully managing their own emotions in addition to patients' ones [9]: in order to do this, a constant revision of treatment plan and strategies is needed. As noted above, the path to recovery is difficult for those affected by EDs and it should be considered in the wide context of development. Only within a solid therapeutic relationship (i.e. embodied simulation and intentional attunement [19]), a new and mature identity can be acquired, progressively replacing the "ED identity".

All articles included in this Special Issue provide a useful contribution to shed light on resistance to treatment in EDs. Halmi [20] acknowledged the importance of severity of the ED psychopathology in resistance and SeguraGarcia and Coworkers [21] investigated the role of personality on long-term prognosis. The relevance of Axis I [22] and substance use [23] comorbidities in predicting resistance has been also addressed. It has been then emphasized the usefulness of a comprehensive multidimensional evaluation (i.e. including the assessment of quality of life) for those patients who are resistant to treatment [24] also considering their stages of change to predict their work alliance abilities [25]. Moreover, emotive and perceptual components have been also investigated: individuals recovered from Anorexia nervosa partially maintain altered emotional facial expressions, mainly as regards positive emotions [26]. Data on how to manage resistance to treatments have also been reported by a clinical overview of the available literature on this topic highlighting four main thematic areas: denial, motivation to change, maintaining factors and treatment outcome, and therapeutic relationship [27]. A multicenter study conducted in UK showed that confidence to change, social functioning, and carers' both expressed emotion and control can predict less resistance, emphasizing the role of family [28]. One contribution advocated the importance of reducing dropouts showing that completion of treatment can predict improved response in Binge Eating Disorder [29] and the role of attention deficit hyperactivity disorder in obese individuals has been debated [30]. Some preliminary results on a modified version of Dialectical Behavioral Therapy focusing on EDs have been also presented [31]. Finally, Marzola et al. [32] underlined the need for evidence-based data on nutritional restoration in Anorexia nervosa in order to further the understanding of the pathophysiology of this disorder and provide clinicians with clear guidelines to minimize resistance.

We believe that BMC Psychiatry can successfully accomplish a wide diffusion of these data and also improve the debate on the topic of resistance to treatment in EDs. The latter is indeed relevant in clinical practice and controversial in research. BMC Psychiatry with its comprehensive framework can strongly help us in this challenge since it is an open access, popular, and peer-reviewed journal. BMC Psychiatry values the psychosomatic approach since it considers articles on all aspects of psychiatric disorders: prevention, diagnosis and clinical management.

So what are the conclusions?

In the ongoing debate on treatment resistance in EDs several aspects remain controversial. If the interplay between genes and environment remains highly unclear, from a therapeutic point of view the main issue then becomes the need of an authentic and solid alliance, particularly with those patients who are resistant to treatment. A major caveat is represented by the need of avoiding collusion or sharp disagreements with patients keeping in mind that the overarching goal is to minimize the risk of therapy failure. The primary aim is to reassure patients that the vital and compensatory aspects of their psychopathology have been deeply understood and their suffering will be carefully considered while planning treatment interventions. Moreover, it is important to measure and compare the expected changes with patients' ability to tolerate distress, minimizing in this way the risk of dropout. As Augustine of Hippo stated many centuries ago, the human mind is conflicting itself, and those affected by an ED represent a paradigm of the conflict between mind and body and life and death, causing often anxiety, helplessness, and compassion in therapists. It is noteworthy that Anorexia nervosa remains an enigma: those symptoms that impair life and body to the point of death can also alleviate inner discomfort. Only a strong knowledge and a firm empathic approach - enhancing a secure attachment - can successfully help therapists to be effective and limit patients' omnipotent and destructive desperation.

What's next? We hope that this special issue can encourage future work on three major lines of research on resistance to treatment in EDs: a) biological factors, b) 
emotions in affected individuals and their families, and c) therapeutic relationship.

Concluding with particular reference to therapeutic alliance, we would like to report here what A. Adler wrote years ago: "I cannot forget what one of my cured patients once answered when I asked him: "What do you believe was the reason that I could succeed to cure you after all these years of misery?". He answered: "I became sick because I had lost all hope. And you gave me hope" [33].

\section{Competing interests}

The authors declare that they have no competing interests.

Received: 25 October 2013 Accepted: 29 October 2013

Published: 7 November 2013

\section{References}

1. Posse PR, Nemeroff CB: The problem of treatment-resistant major psychiatric disorders. In Management of treatment-resistant major psychiatric disorders. Edited by Nemeroff CB. Oxford: Oxford University Press; 2012:3-22.

2. Klump KL, Bulik CM, Kaye WH, Treasure J, Tyson E: Academy for eating disorders position paper: eating disorders are serious mental illnesses. Int J Eat Disord 2009, 42:97-103.

3. Keel PK, Brown TA: Update on course and outcome in eating disorders. Int J Eat Disord 2010, 43:195-204.

4. Treasure J, Russell G: The case for early intervention in anorexia nervosa: theoretical exploration of maintaining factors. Br J Psychiatry 2011, 199:5-7

5. Fassino S, Pierò A, Tomba E, Abbate-Daga G: Factors associated with dropout from treatment for eating disorders: a comprehensive literature review. BMC Psychiatry 2009, 9:67.

6. Arcelus J, Mitchell AJ, Wales J, Nielsen S: Mortality rates in patients with anorexia nervosa and other eating disorders: a meta-analysis of 36 studies. Arch Gen Psychiatry 2011, 68(7):724-731.

7. Zink CF, Weinberger DR: Cracking the moody brain: the rewards of self starvation. Nat Med 2010, 16(12):1382-1383.

8. Kaye WH, Wierenga CE, Bailer UF, Simmons AN, Bischoff-Grethe A: Nothing tastes as good as skinny feels: the neurobiology of anorexia nervosa. Trends Neurosci 2013, 36(2):110-120.

9. Plakun E: Treatment resistance and psychodynamic psychiatry: concepts psychiatry needs from psychoanalysis. Psychodyn Psychiatry 2012, 40(2):183-210

10. Bracken P, Thomas P, Timimi S, Asen E, Behr G, Beuster C, Bhunnoo S, Browne I, Chhina N, Double D, et al: Psychiatry beyond the current paradigm. Br J Psychiatry 2012, 201(6):430-434

11. Fassino S: Psychosomatic approach is the new medicine tailored for patient personality with a focus on ethics, economy, and quality. Panminerva Med 2010, 52:249-264.

12. Brüne M, Belsky J, Fabrega H, Feierman HR, Gilbert P, Glantz K, Polimeni J, Price JS, Sanjuan J, Sullivan R, et al: The crisis of psychiatry-insights and prospects from evolutionary theory. World Psychiatry 2012, 11(1):55-57.

13. Bruch H: Anorexia nervosa: therapy and theory. Am J Psychiatry 1982, 139:1531-1538.

14. Skårderud F: Bruch revisited and revised. Eur Eat Disord Rev 2009, 17:83-88.

15. Strober M: Managing the chronic, treatment-resistant patient with anorexia nervosa. Int J Eat Disord 2004, 36:245-255.

16. Gabbard GO: Psychodynamic Psychiatry in Clinical Practice. 4th edition. Arlington: American Psychiatric Publishing Inc; 2005.

17. Fairburn CG, Cooper Z, Shafran R: Cognitive behaviour therapy for eating disorders: a "transdiagnostic" theory and treatment. Behav Res Ther 2003, 41:509-528.

18. Wildes JE, Marcus MD: Development of emotion acceptance behavior therapy for anorexia nervosa: a case series. Int J Eat Disord 2011, 44:421-427
19. Gallese V: Before and below "theory of mind": embodied simulation and the neural correlates of social cognition. Philos Trans R Soc Lond B Biol Sci 2007, 362:659-669.

20. Halmi KA: Perplexities of treatment resistance in eating disorders. BMC Psychiatry 2013, 13:292

21. Segura-Garcia C, Chiodo D, Sinopoli F, De Fazio P: Temperamental factors predict long-term modifications of Eating Disorders after treatment. BMC Psychiatry 2013, 13:288.

22. Milos GF, Baur V, Muehlebach S, Spindler A: Axis-I Comorbidity is linked to prospective Instability of Diagnoses within Eating Disorders. BMC Psychiatry 2013, 13:295.

23. Gregorowski C, Seedat S, Jordaan GP: A Clinical Approach to the Assessment and Management of Co-morbidEating Disorders and Substance Use Disorders. BMC Psychiatry 2013, 13:289.

24. Mitchison D, Hay P, Engel S, Crosby R, Le Grange D, Lacey H, Mond J, Slewa-Younan S, Touyz S: Assessment of quality of life in people with severe and enduring anorexia nervosa: a comparison of generic and specific instruments. BMC Psychiatry 2013, 13:284.

25. Mander J, Teufel M, Keifenheim K, Zipfel S, Giel KE: Stages of change, treatment outcome and therapeutic alliance in adult inpatients with chronic anorexia nervosa. BMC Psychiatry 2013, 13:111.

26. Davies $\mathrm{H}$, Schmidt U, Tchanturia K: Emotional facial expression in women recovered from anorexia nervosa. BMC Psychiatry 2013, 13:291.

27. Abbate Daga G, Amianto F, De Bacco Carlotta, Delsedime N, Fassino S: Resistance to treatment and change in eating disorders. A review on psychological aspects. BMC Psychiatry 2013, 13:294.

28. Goddard E, Hibbs R, Raenker S, Salerno L, Arcelus J, Boughton N, Connan F, Goss K, Laszlo B, Morgan JF et al: A multi-centre cohort study of short term outcomes of hospital treatment for anorexia nervosa in the UK. BMC Psychiatry 2013, 13:287.

29. Agüera Z, Riesco N, Jiménez-Murcia S, Islam MA, Granero R, Vicente E, Peñas-Lledó E, Arcelus J, Sánchez I, Menchon JM, Fernández-Aranda F: Cognitive behaviour therapy response and dropout rate across purging and nonpurging bulimia nervosa and binge eating disorder: DSM-5 implications. BMC Psychiatry 2013, 13:285.

30. Cortese S, Comencini E, Vincenzi B, Speranza M, Angriman M: Attentiondeficit/hyperactivity disorder and impairment in executive functions: a barrier to weight loss in individuals with obesity? BMC Psychiatry 2013, 13:286.

31. Lynch TR, Gray KLH, Hempel RJ, Titley M, Chen EY, OMahen HA: Radically Open-Dialectical Behavior Therapy for adult Anorexia Nervosa: Feasibility and outcomes from an inpatient program. BMC Psychiatry 2013, 13:293.

32. Marzola E, Nasser JA, Hashim SA, Shih PB, Kaye WH: Nutritional Rehabilitation in Anorexia Nervosa: Implications for Treatment. BMC Psychiatry 2013, 13:290

33. Ansbacher HL: Preface to the diary of Vaslav Nijinsky. Arch Gen Psychiatry 1981, 38:834-835.

\section{doi:10.1186/1471-244X-13-282}

Cite this article as: Fassino and Abbate-Daga: Resistance to treatment in eating disorders: a critical challenge. BMC Psychiatry 13:282.

\section{Submit your next manuscript to BioMed Central and take full advantage of:}

- Convenient online submission

- Thorough peer review

- No space constraints or color figure charges

- Immediate publication on acceptance

- Inclusion in PubMed, CAS, Scopus and Google Scholar

- Research which is freely available for redistribution 